\title{
Recomendações nutricionais para crianças que realizaram transplante de medula óssea
}

\author{
Nutritional recommendations for children who underwent bone marrow transplantation
}

\author{
Edeli Simioni de Abreu ${ }^{1}$, Rosana Farah Simony², Anita Akiko Takahashi ${ }^{3}$, Christiane Ribeiro Balmant \\ dos Santos ${ }^{4}$ \\ 1,2,3,4 UPM - Universidade Presbiteriana Mackenzie
}

\section{Resumo}

A medula óssea é o local onde se produz o sangue. É no interior dos ossos que encontramos as células que darão origem aos glóbulos vermelhos, glóbulos brancos e plaquetas. Essas células são denominadas de células tronco hematopoéticas. Transplante de medula óssea é uma modalidade terapêutica que visa o tratamento da doença com uso de altas doses de quimioterapia associada ou não à radioterapia corporal total. Os pacientes submetidos ao procedimento necessitam de terapia nutricional (TN) individualizada. A TN visa manter e/ou recuperar o estado nutricional no pós-transplante, evitar ou minimizar as deficiências nutricionais decorrentes da quimioterapia e/ou radioterapia, proteger o trato gastrintestinal funcionante, evitar a desnutrição proteicocalórica e proporcionar melhor ingestão oral, fornecendo substrato de forma adequada para recuperação hematopoética e do sistema imune. O objetivo desse estudo foi realizar uma revisão de literatura sobre o assunto, para confecção de um Manual de Terapia Nutricional para pacientes transplantados de medula óssea. O estudo foi realizado no período de outubro a novembro de 2011 , onde foi feito um levantamento bibliográfico dos últimos cinco anos (de 2007 a 2011) sobre recomendações nutricionais para crianças pós transplante de medula óssea, a partir dos dados encontrados foi elaborado um Manual de Terapia Nutricional em pacientes transplantados de medula óssea para uma entidade filantrópica de São Paulo. Foi elaborado, com sucesso, um Manual de Terapia Nutricional para pacientes transplantados de medula óssea, que é um instrumento de orientação alimentar destinado a profissionais da saúde que estejam envolvidos na recuperação desses pacientes.

Palavras Chave: Transplante de Medula Óssea.Terapia Nutricional. Neoplasias.

\begin{abstract}
Bone marrow is the location where the blood is produced. It is inside of the bones where we found the cells that give rise to red blood cells, white blood cells and platelets. These cells are called hematopoietic stem cells. Bone marrow transplantation (BMT) is a therapeutic modality for the treatment of diseases with use of high-dose chemotherapy with or without total body radiotherapy. The patients who underwent the procedure require individualized nutritional therapy. The nutritional therapy aim to keep and/or recover the nutritional status in post-transplant, avoid or minimize nutritional deficiencies resulting from chemotherapy and/or radiotherapy, to protect the gastrointestinal tract functioning, avoid malnutrition and provide better oral intake, providing substrate appropriately for haematopoietic recovery and immune system. The aim of this study was to conduct a literature review on the subject, for the production of a Nutritional Therapy Handbook for bone marrow transplant patients. The study was conducted in 2011 from October to November, it was made a bibliographical survey of five years (2007 to 2011) on nutritional recommendations for children after bone marrow transplant, from data found it was drafted a Nutritional Therapy Handbook for bone marrow transplant patients for a philanthropic entity of São Paulo. It was drawn up, with success, a Nutritional Therapy Handbook for bone marrow transplant patients, which is an instrument of food guidance for health professionals who are involved in the recovery of these patients.
\end{abstract}

Keywords: Bone Marrow Transplantation.Nutrition Therapy.Neoplasms.

\section{INTRODUÇÃO}

\subsection{O câncer}

No início do século XX o câncer começou a ser estudado, porém não tão profundamente quanto às doenças da época, como a sífilis. O tratamento do câncer teve inicio na área de dermatologia com foco no tratamento de câncer de pele, pois muitos médicos não tinham muito conhecimento na área, além de não possuírem dados epidemiológicos concisos. Porém a

Recebido em 26/02/2012; revisado em 02/04/2012.

Correspondência / Correspondence: Edeli Simioni de Abreu..Alameda São Caetano, 857 - apto. 43 - São Caetano do Sul São Paulo - SP. CEP: 09560-105 Telefone: (11) 4221-7535 ou Celular:

(11) 98434-9393.Email: edelisabreu@gmail.com partir do ano de 1920, as preocupações médicas sobre o câncer deixaram de ser apenas voltadas para a pele e dando assim origem a iniciativas na área. Deste periodo em diante, aumentou-se o número de profissionais, foram criadas instituições voltadas para o tratamento e estudo do câncer e um aumento nos números de reuniões científicas e congressos na área (TEIXEIRA, 2010).

O câncer é uma doença causada pelo crescimento desordenado de células (quando malignas) que invadem os tecidos e órgãos, podendo espalhar-se para todas as 
regiões do corpo (metástase). Essas células tendem a ser muito agressivas e incontroláveis, dando origem à formação de tumores, que é o acúmulo de células cancerosas ou neoplasias malignas (ICESP, INCA, 2011).

As diferenças entre os cânceres estão nos vários tipos de células do corpo. As causas são multifatoriais, ou seja, podem ter influência externas (meio ambiente, estilo de vida, hábitos alimentares, irradiação solar, fatores ocupacionais entre outros) e também internas ao organismo (genética), estando uma associada á outra. De todos os casos 80 a $90 \%$ são associados aos fatores ambientais (ICESP, 2011; INCA, 2011; FONSECA, 2010).

\subsection{Câncer infantil}

Atualmente o câncer é a 2a causa de morte em crianças e adolescentes de 1 a 19 anos, porém estimase que aproximadamente $70 \%$ das crianças acometidas de câncer podem ser curadas quando diagnosticadas com antecedência e tratadas em centros especializados. Após o tratamento adequado a maioria das crianças possui boa qualidade de vida (INCA, 2011).

Diferentemente dos adultos, os cânceres em crianças afetam as células do sistema sanguíneo e os tecidos de sustentação, além disso, as doenças malignas em crianças, por serem predominantemente de base embrionária, são constituídas de células indiferenciadas, que geralmente determinam uma melhor resposta aos métodos terapêuticos. As neoplasias infantis mais frequentes são: leucemia, tumores cerebrais, linfomas, neuroblastomas, sarcomas de partes moles, tumor de Wilns, tumores ósseos e retinoblastomas (INCA, 2011).

O tratamento dos cânceres sanguíneos em crianças podem trazer alguns efeitos endócrinos negativos (SILVEIRO-MIACHON, 2009). Um estudo realizado por Kuperman e colaboradores (2010) verificaram em crianças e adolescentes, alguns efeitos endócrinos tardios após o tratamento de neoplasias malignas, sendo eles a baixa estatura, puberdade precoce, tireoidopatias, obesidade, diabetes, panhipopituitarismo e puberdade atrasada, sendo que esses efeitos tardios podem estar positivamente relacionadas à qualidade da dieta antes e durante o tratamento. Muitos estudos demonstram que os pacientes em tratamento quimioterápico referem sintomas como enjoo e náuseas que levam a uma baixa ingestão de alimentos e nutrientes.

\subsection{O Transplante de Medula Óssea}

A medula óssea é o local onde se produz o sangue. É no interior dos ossos que encontramos as células mãe do sangue, ou melhor, as células que darão origem aos glóbulos vermelhos, glóbulos brancos e plaquetas. Essas células mãe são denominadas de células progenitoras ou células tronco hematopoéticas (MASSUMOTO, 2011).
Transplante de medula óssea é uma modalidade terapêutica que visa o tratamento da doença com uso de altas doses de quimioterapia associada ou não à radioterapia corporal total. Existem três tipos de transplante: o alogênico, o autólogo e o singênico. No transplante alogênico, a medula óssea é retirada de um doador previamente selecionado por testes de histocompatibilidade, normalmente identificado entre os familiares ou em bancos de medula óssea. No transplante autólogo, a medula óssea ou as células tronco periféricas são retiradas do próprio paciente, armazenadas e reinfundidas após o regime de condicionamento. $\mathrm{O}$ transplante de medula óssea entre gêmeos univitelinos é denominado singênico. Mais recentemente, o transplante com células do cordão umbilical vêm sendo empregado em alguns centros para o tratamento de crianças e adultos jovens, principalmente portadoras de leucemias agudas. 0 objetivo é promover a introdução de novas células no organismo do receptor, gerando uma mistura celular e a seguir, como as células introduzidas são mais resistentes, elas passam a proliferar e destruir as células tumorais remanescentes no receptor. A indicação do transplante depende, em geral, da fase da doença em que os pacientes se encontram (MASSUMOTO, 2011).

O transplante de células-tronco hematopoéticas (TCTH) é um procedimento com resultados imediatos e de longo prazo afetados pelo diagnóstico, estágio da doença, tipo de transplante (autólogo ou alogênico), grau de histocompatibilidade do doador, regime de condicionamento (mieloablativo, não mieloablativo ou de intensidade reduzida), fonte de células-tronco (medula óssea, sangue periférico ou sangue do cordão umbilical da placenta), idade, tratamento prévio e estado nutricional. No procedimento, os pacientes recebem quimioterapia associada ou não a radioterapia anterior ao transplante, com o objetivo de erradicar ao máximo as células tumorais residuais e promover a imunossupressão das células imunologicamente ativas (ALBERTINI, 2010).

A imunossupressão e a toxicidade intensa predispõem os transplantados a graves complicações, como, por exemplo, infecções, sangramentos, anemias, desenvolvimento da doença do enxerto-contrahospedeiro (DECH) além da mucosite evidente no período de neutropenia e de aplasia (ALBERTINI, 2010).

Os pacientes submetidos ao TCTH rotineiramente necessitam de terapia nutricional (TN) individualizada, devendo ser iniciada imediatamente desde o prétransplante na vigência de risco nutricional ou da desnutrição. A TN visa manter e/ou recuperar o estado nutricional no pós-transplante, evitar ou minimizar as deficiências nutricionais decorrentes da quimioterapia e/ou radioterapia, proteger o trato gastrintestinal funcionante, evitar a desnutrição proteicocalórica e proporcionar melhor ingestão oral, fornecendo substrato de forma adequada para recuperação hematopoética e do sistema imune (ALBERTINI, 2010). 


\section{OBJETIVOS}

Realizar uma revisão de literatura sobre recomendações nutricionais para crianças pós transplante de medula óssea, para confecção de um Manual de Terapia Nutricional em pacientes transplantados de medula óssea.

\section{METODOLOGIA}

O estudo foi realizado no período de outubro a novembro de 2011, onde foi feito um levantamento bibliográfico dos últimos cinco anos (de 2007 a 2011) sobre recomendações nutricionais para crianças pós transplante de medula óssea, com auxílio de bases de dados do Medline, Lilacs e sites de instituições e hospitais que realizam tratamento para o câncer. As palavras chave utilizadas foram: Transplante de medula óssea, TMO infantil, terapia nutricional para transplantados medulares, câncer infantil e câncer. A partir dos dados encontrados foi elaborado um Manual de Terapia Nutricional em pacientes transplantados de medula óssea para uma entidade filantrópica de São Paulo.

\section{RESULTADOS E DISCUSSÃO}

O levanto bibliográfico de artigos científicos publicados entre 2006 a 2011 realizado permitiu a confecção do um Manual de Terapia Nutricional em pacientes transplantados de medula óssea, que se encontra ao lado.

Os pacientes pediátricos que passaram pelo tratamento quimioterápico ou radioterápico possuem uma grande chance de sobreviver ao câncer, porém estudos demonstram que a obesidade é um evento reconhecido após o tratamento, alguns dos fatores são: lesões hipotalâmicas que consequentemente alterará as funções de alguns hormônios que regulam o processo de ingestão e absorção de nutrientes, rebote precoce de adiposidade que seria utilizado no momento do estirão do crescimento, hiperinsulinemia e regulação da leptina (SIVIERO-MIACHO; SPINOLA-CASTRO; GUERRA-JUNIOR, 2009).

A terapia para o transplante de medula é invasiva, com isso é necessário que o paciente esteja em bom estado nutricional. Segundo um estudo realizado por Garófalo e colaboradores (2006), demonstraram que os pacientes que recebem o TMO apresentam um aumentos dos níveis de triglicérides e glicose e diminuição dos níveis de HDL colesterol que podem atrapalhar o processo de cura.

Alguns estudos demonstram que a glutamina tem um efeito benéfico para pacientes que realizam o TMO, a glutamina demonstrou uma redução na intoxicação gastrointestinal e consequentemente uma melhora na absorção de nutrientes que levam a uma recuperação mais rápida (GOMES, 2006).

Como já mencionado os paciente que realizam o TMO sofrem de mucosite e consequentemente dificuldades para se alimentar, isso devido ao processo quimioterápico que acaba lesando a mucosa gastrointestinal. Por esse motivo é que muitos pacientes acabam utilizando a nutrição parenteral total ou enteral dependendo da tolerância (GOMES, 2006).

Sendo assim as recomendações gerais são (HOSPITAL SAMARITANO, 2011):

- Boa alimentação e hidratação, escolhendo alimentos de maior valor nutritivo, ricos em ferro, saudáveis e rigorosamente higienizados para o consumo.

- Comer pequenas porções em intervalos maiores, preferir alimentos com maior valor calórico, evitar ingestão de líquidos entre as refeições, evitar alimentos com sabor e odores muito fortes.

- Observar a data de validade das embalagens, mantendo uso individual.

A alimentação adequada é essencial para auxiliar na recuperação dos pacientes em tratamento quimioterápico, dessa forma é preciso evitar a ingestao de alimentos que apresentam alto poder de contaminação, isso inclui, além das frutas e verduras cruas, o leite e o ovo. Pois um estudo realizado por Tchana, Moundipa e Tchouangup (2010) demonstrou que o leite e os ovos possuíam níveis de aflatoxina acima do limite tolerado.

É de extrema importância que os pacientes submetidos a um tratamento quimioterápico esteja em um estado nutricional adequado, pois, muitos estudos demonstram que devido ao procedimento quimioterápico muitas crianças passam a apresentar desnutrição energético protéica. Alguns dos motivos são baixa ingestão dos alimentos, queda do gasto energético, da absorção e metabolismo dos nutrientes, toxicidade oral e gastrintestinal, nefrotoxicidade e surgimento de infecções. Devido a esses motivos é necessária uma intervenção nutricional efetiva e precoce, pois além da melhora do estado nutricional do paciente evita a diminuição das doses das drogas, o atraso dos ciclos quimioterápicos, o aumento do risco de toxicidade, as infecções e a morte (GARÓFOLO, 2005).

$A$ avaliação nutricional nesses pacientes é de baixa exatidão, porém alguns estudos demonstram a utilização de exames bioquímicos como o balanço nitrogenado, porém o mesmo não poderá ser avaliado em indivíduos com casos de diarreia e vômito excessivo devido à modificação dos fluidos corporais (ALBERTINI, 2010).

O estudo realizado por Sommacal e colaboradores (2009) verificaram o melhor e mais adequado método e quais as frequências de aferição ideal para a avaliação nutricional. Foram feitas a aferições em 17 indivíduos com idade maior ou igual a 18 anos e verificou-se que os indivíduos tiveram perda de peso e a média de ingestão calórica foi de $87 \%$ do gasto energético basal para as mulheres e $113 \%$ para os homens. Em relação às medidas antropométricas 


\section{Manual de Terapia Nutricional em pacientes transplantados de medula óssea}

\section{Recomendações nutricionais para os pacientes transplantados}

- Por se tratar de uma terapia invasiva é necessário que o paciente esteja em bom estado nutricional. Segundo um estudo realizado por Grófolo et al. (2005), demonstrou que os paciente que recebem o TMO apresentam um aumentos dos níveis de triglicérides e de glicose que podem atrapalhar o processo de cura pois os mesmos em alta concentração causam falência ou disfunção orgânica, alem de apresentarem altos níveis de triglicérides e de glicose o estudo demonstrou uma diminuição dos níveis de HDL colesterol o que pode piorar ainda mais a situação do paciente.

- Já alguns estudos demonstram que a glutamina tem um efeito benéfico para pacientes que realizam o TMO, a glutamina demonstrou uma redução na intoxicação gastrointestinal e consequentemente uma melhora na absorção de nutrientes que levam a uma recuperação mais rápida (GOMES, 2006).

- E Como já mencionado os paciente que realizam o TMO sofrem de mucosite e consequentemente dificuldades para se alimentar, isso devido ao processo quimioterápico que acaba lesando a mucosa gastrointestinal. Por esse motivo é que muitos pacientes acabam utilizando a nutrição parenteral total ou enteral dependendo da tolerância.

- Sendo assim as recomendações gerais são:

- -Boa alimentação e hidratação, escolhendo alimentos de maior valor nutritivo, ricos em ferro, saudáveis e rigorosamente higienizados para o consumo.

- - Comer pequenas porções em intervalos maiores, preferir alimentos com maior valor calórico, evitar ingestão de líquidos entre as refeições, evitar alimentos com sabor e odores muito fortes.

- Observar a data de validade das embalagens, mantendo uso individual.

\section{Conduta nutricional}

- Não ingerir nenhum alimento cru durante o período do transplante e enquanto não ocorrer à recuperação dos leucócitos, incluindo caldo de cana, água de coco em natura, sucos de polpa, alimentos crus, leites não pasteurizados e queijos crus 4 .

- Após a recuperação leucocitária e, por um período de 6 a 12 meses, após o transplante, os pacientes deverão seguir as seguintes orientações 4 :

- Consumir frutas de casca média a grossa, poderão ser oferecidas cruas após higienização com hipoclorito de sódio. Exemplo: laranja, mexerica, melão, melancia, banana, manga, mamão e maçã.

- Não consumir alimentos com maior risco de contaminação ou com maior dificuldade para realizar a desinfecção. Exemplo: brócolis e couve flor, mesmo quando cozidos e frutas de casca fina (morango, ameixa, pêssego, uva, framboesa e jabuticaba).

- Consumir água mineral para evitar problemas de purificação que ocasionalmente ocorrem com os filtros de água.

- Os alimentos industrializados após abertos não devem ser consumidos. Deve-se preferir o consumo destes em embalagens individuais ou desprezar o restante do alimento após aberto.

- Frios fatiados em laminas de padarias e mercados. Comprá-los em peças inteiras e lacradas, preferencialmente embalados a vácuo.

- Nunca consumir ovos crus ou mal passados, sendo importante atentar-se para preparações que contenham em sua composição a gema ou a clara do ovo cru.

- As carnes devem estar bem cozidas, sendo importante não consumi-las sob a forma mal passada ou crua, inclusive os defumados como as salsichas.

- Consumir legumes e folhas sempre cozidas, evitando os alimentos crus.

- As conservas devem ser cozidas antes de consumidas. Exemplo: milho, aspargo, palmito, champignon.

- Preferir pipocas preparadas em microondas.

- Temperos desidratados não devem ser consumidos sem cocção. Exemplo: orégano, canela em pó, pimenta do reino.

- Não consumir frutas secas, cristalizadas e oleaginosas.

- Não consumir salgadinhos de pacotes de marcas não idôneas

- Os saquinhos de chás devem ser fervidos para prepará-los

\section{Procedimento adequado para ingestão de frutas}

- A casca de estar integra, sem furos, amassados ou escoriações.

- Lavar os alimentos em água corrente e potável para remover sujidades aderidas e reduz o número de bactérias.

- Esterilizar os alimentos conforme a portaria CVS-6/99 que indica soluções cloradas para a desinfecção de alimentos. Dentre as opções recomendadas, o hipoclorito de sódio a $1 \%$ pode ser utilizado com diluição de 20 $\mathrm{ml}$ de solução em 1 litro de água.

- Sugestão: Utilizar solução de hipoclorito de sódio vendido em estabelecimentos comerciais e seguindo orientação de diluição do fabricante.Após a desinfecção descascar estes alimentos antes de servir. 
verificou-se que o calculo do índice de massa corporal (IMC) não é recomendado, já a circunferência do braço e dobra cutânea do tríceps apresentaram diferenças significativas entre a primeira e a terceira medida sendo assim o melhor método. Concluindo assim que nenhum método é livre de falhas e que cada local deve identificar a avaliação mais adequada à realidade e os intervalos quinzenais apresentaram-se mais efetivos.

Além do estado fisiológico da criança estudos mostram a importância de uma boa qualidade de vida, pois quando a criança apresenta uma baixa autoestima à família, em especial, que serve como base de sustentação para a criança/ adolescente, começa a se sentir incapacitado de satisfazer as necessidades relacionadas aos cuidados de saúde (HANSSON et al., 2011).

Um estudo realizado por Silva e colaboradores (2009) verificou a qualidade de vida das crianças e adolescentes em tratamento e os familiares assim aplicou questões quali-quantitativas em uma Unidade de Onco-Hematologia do Hospital Infantil Nossa Senhora da Glória, desta forma observou que a doença exerce um grande impacto na vida da família e percebeuse que em $74 \%$ dos casos há uma modificação na alimentação tanto do enfermo quanto da família, isso devido ao grande cuidado com os alimentos para esse público, $72 \%$ possuía alteração no sono e $69 \%$ buscavam um apoio espiritual.

O estudo de Comaru e Monteiro (2008) verificou que devido à patologia da criança muitas famílias acabam entrando em conflito, um dos motivos seria devido à crise de sobrevivência que causa uma sobrecarga das atividades de cuidado, além disso constatou que a condição de baixa renda aumenta a sobrecarga.

Diante de muitas dores e baixa autoestima causada pela doença algumas instituições utilizam métodos como a brinquedoteca para aliviar a tensão existente nesse ambiente, tirando assim a condição passiva de doente e para uma condição de melhora do tratamento, pois o ato de brincar contribui para o desenvolvimento e terapia (MELLO; VALLE; 2010).

\section{CONCLUSÃO}

Foi elaborado, com sucesso, um Manual de Terapia Nutricional para pacientes transplantados de medula óssea, que é um instrumento de orientação alimentar destinado a profissionais da saúde que estejam envolvidos na recuperação desses pacientes.

\section{REFERÊNCIAS}

ALBERTINI, Sílvia Maria. O transplante de células-tronco hematopoéticas e o fator Anutricional na evolução dos pacientes. Rev. Bras. Hematol. Hemoter., São Paulo, v. 32, n. 1, p. 8-9, Feb. 2010.

BRUNE, Waleska Luiza. Transplante de medula óssea autogênico em crianças e adolescentes: orientações para pacientes e familiares. 2010. 87p. Monografia (Conclusão de curso de enfermagem) Universidade Federal do Rio Grande do Sul, Porto Alegre, 2010.

COMARU, Natália Rocha Chagas; MONTEIRO, Ana Ruth Macêdo. O cuidado domiciliar à criança em quimioterapia na perspectiva do cuidador familiar. Rev. Gaúch. Infirm., Porto Alleger, v. 29, n. 3, p. $423-30,2008$.

ENGELEN, V. et al.. Health-Related Quality of Life After Completion of Successful Treatment for Childhood Cancer. Pediatr. Blood. Cancer., Hoboken, v. 56, n. 4, p. 646-653, 2011.

FONSECA, L.A.M.; NETO, J.E.; FILHO, V.W. Tendências da mortalidade por câncer nas capitais dos estados do Brasil, 1980-2004. Ver. Assoc. Méd. Bras., São Paulo, v. 56, n. 3, p. 309-312, 2010.

GARÓFOLO, A. et al. Prevalência de desnutrição em crianças com tumores sólidos. Rev. Nutr., Campinas, v. 18, n. 2, p. 193-200, 2005.

GARÓFOLO, A.; ALVES, F.R.; REZENDE, M.A.C. Suplementos orais artesanais desenvolvidos para pacientes com câncer: análise descritiva. Rev. Nutr., Campinas, v. 23, n. 4, p. 523-533, 2010.

GÓMEZ CANDELA, C.; CASTILLO, R.; COS, A. I.; et al. Efectos de la glutamina parenteral en pacientes sometidos a trasplante de médula ósea. Nutr. Hosp., Madrid, v. 21, n. 1, p. 13-21, 2006.

HANSSON, H.; et al. Hospital-Based Home Care for Children With Cancer. Pediatr. Blood. Cancer., Hoboken, v. 57, n. 3, p. 369-377, 2011.

INSTITUTO NACIONAL DE CÂNCER - INCA(Brasil). Disponível em:

<http://www.inca.org.br>. Acesso em: 21 de out. 2011.

INSTITUTO DO CÂNCER DO ESTADO DE SÃO PAULO - ICESP. Disponível em: <http://www.icesp.org.br> Acesso em: 21 de out. 2011.

KUPERMAN, H. et al. Avaliação dos principais efeitos endócrinos tardios em crianças e adolescentes sobreviventes ao tratamento de neoplasias malignas. Arq. Bras. Endocrinol. Metab., São Paulo, v. 54, n. 9, p. $819-825,2010$.

LEE MLM. Leucemias agudas na infância. Pediatr. Mod., São Paulo, v. 35, p. 616-21, 1999.

MASSUMOTO, C. M.; PEREIRA, M. A. Transplante de Medula Óssea. Disponível em <http://hope.org.br/transplante-de-medulaossea/>.Acesso em: 10 out. 2011.

MELO, de Lione Melo; VALLE, Elizabeth Ranier Martins do Brinquedoteca como possibilidade para desvelar o cotidiano da criança com câncer em tratamento ambulatorial. Rev. Esc. Enferm. USP., São Paulo, v. 44, n. 2, p. 517-525, 2010.

HOSPITAL SAMARITANO. Serviço de Gastronomia e Nutrição: orientação nutricional para pacientes transplantados de medula óssea. Disponível em: <http:// www.espacomedico.samaritano.org.br>.

SILVA, F.A.C. et al. Representação do processo de adoecimento de Crianças e adolescentes oncológicos junto aos Familiares. Esc. Anna Nery Rev. Enferm., Rio de Janeiro, v.13, n.2, p. 334-341, 2009.

SIVIERO-MIACHON, A.A.; SPINOLA-CASTRO, A.M.; GUERRA-JUNIOR, G. Adiposity in childhood cancer survivors: insights into obesity physiopathology. Arq. Bras. Endocrinol. Metab., São Paulo, v.53, n.2, p.190-200, 2009.

SOMMACAL, H. M. et al. Comparação de métodos de avaliação nutricional empregados no acompanhamento de pacientes submetidos a transplante de células-tronco hematopoéticas alogênico. Rev. Bras. Hematol. Hemoter., São Paulo, v.32, n. 1, p.5055, feb. 2010. 
TCHANA, A.N.; MOUNDIPA, P.F.; TCHOUANGUEP, F.M. Aflatoxin Contamination in Food and Body Fluids in Relation to Malnutrition and Cancer Status in Cameroon. Int. J. Environ. Res. Public Health. Basel, Switzerland, v.7, p.178-188, 2010.
TEIXEIRA, Luiz Antonio. Controle do câncer no Brasil na primeira metade do século xx. Hist. Ciênc. Saúde-Manguinhos., Rio de Janeiro. v17, supl.1, p.13-31, jul. 2010. 